\title{
Towards interrelationship of grain size, cell parameters and flow stress in type 316L stainless steel
}

\author{
B.P. Kashyap ${ }^{\text {a,* }}$ \\ a Department of Metallurgical Engineering and Materials Science, Indian Institute of Technology, Bombay, Mumbai 400076 , \\ India
}

\begin{abstract}
In order to investigate the interrelationship amongst grain size, cell size, cell wall thickness and flow stress in type 316L stainless steel, tensile specimens of grain sizes 3.1-86.7 $\mu \mathrm{m}$ were deformed to a strain of 0.34 at the temperatures 297,673 and $973 \mathrm{~K}$ and at a strain rate $1 \times 10^{-4} \mathrm{~s}^{-1}$. The cell wall thickness is found to be larger than the cell interior size but the two are mutually related and only marginally decrease with the increase in grain size. The difference in the distributions of dislocations and cell structure in the vicinity of grain boundaries and in the grain interior leads to a variation in their relative contributions to strengthening. The smaller cell interior sizes and thicker cell walls result in a greater contribution of grain interior to strengthening of polycrystalline material than the grain boundaries, with the maximum effect observed at $673 \mathrm{~K}$ due to dynamic strain aging.
\end{abstract}

\section{Introduction}

The presence of grain boundaries in polycrystalline materials is known to contribute to strengthening at low temperatures according to the HallPetch-type relationship [1,2], which is found to be true not only at yield point but at larger strain levels also. However, depending on test temperature, the substructural evolution during deformation introduces cell walls or subgrain boundaries at large strains, which act as the new interfaces that inhibit dislocation motion. The strength of cell walls and subgrain boundaries, in comparison to the grain boundary resistance, was reported [3] to be much less. Typically, the magnitudes of the Hall-Petch slope, on the basis of such substructures, were only $20-50 \%$ of that for the grain boundaries. In spite of the substantially less resistance provided to dislocation motion by cell walls and subgrain boundaries, the effect of cell size and subgrain size dominate over grain boundary strengthening of polycrystalline materials, when the proportion of the new interfaces becomes large enough upon substructural refinement. For example, strengthening in copper was caused mainly by substructural interfaces rather than grain 
boundaries, when the cell/subgrain size was found to be $0.4 \mu \mathrm{m}$ or less [4]. It may be noted here that, unlike the grain boundary thickness of 5-10A, the cell wall thickness varies over a wide range depending on deformation condition [5,6]. However, in the literature, only the cell size is used in relating its effect on flow stress, and often no consideration is given to the cell wall thickness. This is in spite of the fact that the cell interior and cell wall, with different dislocation densities and local stresses, are treated as composite-type material [5,7-9].

In type 316L stainless steel, substructural evolution was investigated $[5,6]$ as a function of strain, temperature and grain size, and the flow stress, especially at lower temperatures, was reported to be dependent on cell wall thickness. The cell structure was also found to vary with grain size but the flow stress was related to grain size and the workhardening behavior only. No attempt was made to quantify the substructural parameters to relate with flow stress. In view of the cell structure developed at large strains in this material, in spite of the low stacking fault energy, it would be interesting to examine how the cell size and wall thickness depend on grain size and how they themselves influence the flow stress. Therefore, it is aimed here to examine the substructures developed at a large tensile strain and quantify the same in order to correlate with the observed flow hardening in type $316 \mathrm{~L}$ stainless steel.

\section{Experimental}

Type 316L stainless steel, whose composition is given elsewhere [6], was obtained in the form of $12.5 \mathrm{~mm}$-thick plate. The same was rolled in several passes to $1.3 \mathrm{~mm}$-thick sheet at room temperature. Tensile specimens were machined with gage length of $25.4 \mathrm{~mm}$ and gage width of $5.4 \mathrm{~mm}$. Tensile tests were conducted at a constant true strain rate of $1 \times 10^{-4} \mathrm{~s}^{-1}$ with an Instron universal testing machine. Test temperatures of 297, 673 and $973 \mathrm{~K}$ used here were controlled to an accuracy of $\pm 1 \mathrm{~K}$. All the specimens were deformed to a fixed strain of 0.34. Upon completion of straining, the specimens were unloaded quickly and cooled by a jet of liquid nitrogen so as to freeze the substructures developed.

In order to get the various grain sizes, the tensile specimens were annealed for $15 \mathrm{~min}$ to $310 \mathrm{~h}$ in the temperature range of 1173 to $1573 \mathrm{~K}$. The methods followed for specimen preparation for optical metallography, and transmission electron microscopy (TEM) are described elsewhere [5,6]. The grain sizes were measured using a Leitz Tas Plus image analyzer and the grain sizes are reported here with an accuracy of $\pm 5 \%$ at $95 \%$ confidence level. No twins were noted to be present in the microstructures used for measuring grain sizes. TEM specimens were examined in a JEOL $2000 \mathrm{FX}$ scanning transmission electron microscope operating with an accelerating potential of $200 \mathrm{kV}$. For representing the substructures of each deformed tensile specimen, a large number of photographs were taken at suitable magnifications. The sizes of at least two hundred cell interiors and cell walls were measured individually for representing the cell size and wall thickness developed in any tensile specimen.

\section{Results}

Tensile properties of type $316 \mathrm{~L}$ stainless steel under the test and microstructural conditions used here were presented in detail earlier [5,6]. Specifically discussed were the Hall-Petch-type relationship and the substructural evolution as a function of strain and test temperature. For the sake of continuity, a summary of the stress-strain curves and the substructures observed from the tensile specimens of the smallest grain size of $3.1 \mu \mathrm{m}$ and the largest grain size of $86.7 \mu \mathrm{m}$, upon deformation to a strain of $34 \%$ at the three test temperatures of 297, 673 and $973 \mathrm{~K}$, are presented in Figs. 1-3. As expected, the stress-strain curves, Fig. 1, show an increase in flow stress with the decreases in grain size and test temperature. The substructures, both at low, Fig. 2(a-e), and high, Fig. 3(a-e), magnifications reveal different morphology, size and distribution of cells or cell-like structures as a function of grain size and test temperature. It is apparent from the micrographs in Figs. 2 and 3 that the high dislocation-density areas, constituting the 


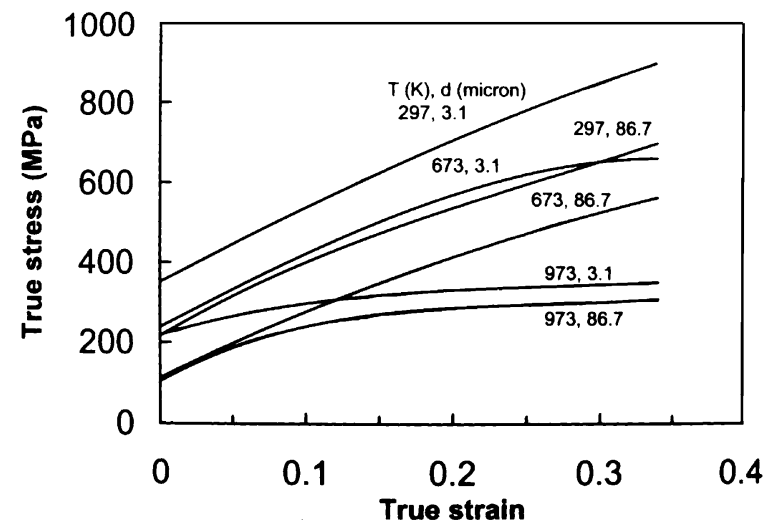

Fig. 1. True stress-true strain curves for the smallest $(3.1 \mu \mathrm{m})$ and largest $(86.7 \mu \mathrm{m})$ grain size samples deformed at three test temperatures of 297, 673 and $973 \mathrm{~K}$. Flow stress is seen to increase with the decreases in grain size and test temperature.

cell wall structure, are very large. Qualitatively, the dislocation-dense area (cell wall) and dislocationlean area (cell interior) appear analogous to the constituent phases in the massive two-phase structures or the constituents of comparable volume proportions in the composite-type materials. In the present results, the cell structure, consisting of cell interior and cell wall, was quantified in an attempt to correlate with the observed flow hardening caused by plastic deformation at a fixed but large tensile strain interval, viz. from yielding $(\varepsilon=$ 0.002 ) to $\varepsilon=0.34$.

\subsection{Effect of grain size on flow stress and flow hardening}

Tensile specimens of different grain sizes $(\mathrm{d}=$ 3.1, 5.1, 7.3, 16.8, 33.1 and $86.7 \mu \mathrm{m}$ ) were deformed to the fixed strain of $34 \%$ at the true constant strain rate $(\dot{\varepsilon})$ of $1 \times 10^{-4} \mathrm{~s}^{-1}$ separately at three test temperatures (T) of 297, 673 and $973 \mathrm{~K}$. From the stress-strain curves (presented in detail in ref. [6] and summarized in Fig. 1), the flow stresses at yield point, i.e. $\varepsilon=0.002$, and at the terminal strain level of 0.34 are plotted in Fig. 4(a). As expected, the flow stresses at both the strain levels decrease with the increases in grain size and test temperature; the decrease being rapid in the fine grain size range up to $16.8 \mu \mathrm{m}$. However, the yield stresses at 673 and $973 \mathrm{~K}$ are not found to be different but, at the same temperatures, the flow stresses at $\varepsilon=0.34$ are quite different. As reported earlier [6], the analysis of flow stress as a function of grain size at both the strains were found to follow the Hall-Petch-type relationship [1,2].

Plotted in Fig. 4(b) are the differences in flow stresses $(\Delta \sigma)$ between $\varepsilon=0.34\left(\sigma_{0.34}\right)$ and $\varepsilon=$ $0.002\left(\sigma_{0.002}\right)$ as a function of grain size. At 297 $\mathrm{K}, \Delta \sigma$ is found to decrease with the increase in grain size whereas the same increases with grain size at the higher test temperatures. Both the yield stress and flow stress at $\varepsilon=0.34$ vary with grain size but the nature of variation in flow stress between these limiting strains should depend on substructure development. The nature of substructure evolution during plastic deformation depends on initial structure, which involves grain as well as substructure. Since the effect of initial structure is reflected through the yield stress values, the effect of grain size on flow hardening in terms of the evolved substructure can be best realized by normalizing $\Delta \sigma$ with the corresponding values of $\sigma_{0.002}$. It may be noted here that substructural evolution also occurs in the microyielding region but its effect gets integrated at macroyielding. In view of this, the plot of normalized flow hardening $\left(\Delta \sigma / \sigma_{0.002}\right)$ as a function of grain size is also included in Fig. 4(b). It is seen that $\Delta \sigma / \sigma_{0.002}$ increases with grain size at all the test temperatures but, this time, the curve at $673 \mathrm{~K}$ shows the maximum flow hardening behavior.

\subsection{Effect of grain size on cell structure}

TEM specimens prepared from the tensile specimens, deformed to $\varepsilon=0.34$ at $\dot{\varepsilon}=1 \times 10^{-4} \mathrm{~s}^{-1}$ and $\mathrm{T}=297,673$ and $973 \mathrm{~K}$, were examined to find the effects of grain size and test temperature on cell interior size $\left(\mathrm{d}_{\mathrm{ci}}\right)$ and cell wall thickness $\left(\mathrm{d}_{\mathrm{w}}\right)$. The TEM micrographs in Figs. 2 and 3 illustrate the substructures obtained at low and high magnifications, respectively, as a function of grain size (a-b, c-d and e-f for grain sizes of $3.1(a, c, e)-$ $86.7(\mathrm{~b}, \mathrm{~d}, \mathrm{e}) \mu \mathrm{m})$ and test temperature (a-c-e and bd-e for T $=297(a, b)-673(c, d)-973(e, f) K)$. The histograms of cell interior size and wall thickness were obtained for all the grain sizes $(3.1,5.1,7.3$, $16.8,33.1$ and $86.7 \mu \mathrm{m})$ but for the sake of clarity 

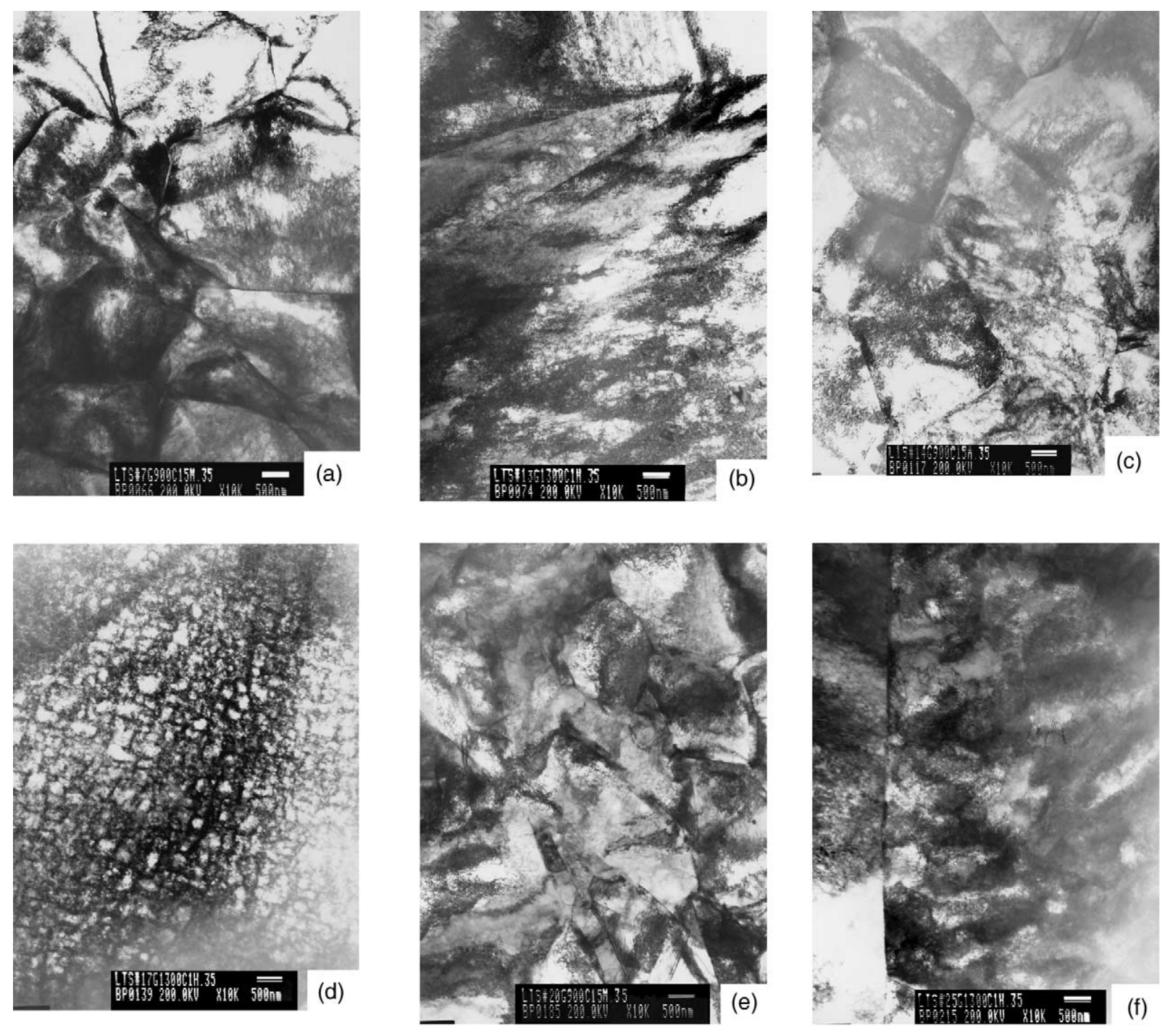

Fig. 2. Substructures developed in tensile specimens of the smallest (3.1 $\mu \mathrm{m}$; a,c,e) and largest ( $86.7 \mu \mathrm{m}$; b,d,f) grain sizes upon deformation to $\varepsilon=0.34$ at three test temperatures of $297(\mathrm{a}, \mathrm{b}), 673$ (c,d) and $973 \mathrm{~K}(\mathrm{e}, \mathrm{f})$. It is seen that the dislocations occupy large proportions of area, constituting thick cell walls. (Low magnification).

in presentation of histograms the same are given for only three grain sizes of $3.1,7.3$ and $86.7 \mu \mathrm{m}$ in Fig. 5(a-f). These grain sizes were selected because the variation in stress as a function of grain size (Fig. 4(a)) is rapid in the lower grain size range and sluggish in the upper grain size range. The histograms are found to exhibit frequency peaks towards the minimum values of $d_{c i}$ and $d_{w}$. The $d_{c i}$ and $d_{w}$ size-range broadening is seen to be more for finer grain size than that for coarser grain size. Also, the frequency values for both $d_{c i}$ and $d_{w}$ are generally larger for the finer grain size than that for the coarser grain size. At $673 \mathrm{~K}$, the frequency of finer cells appears to be greater than that at other temperatures. Also, there appears a wider variation in the wall thickness than the cell interior size, suggesting the formation of a large number of cells with thicker walls.

An attempt was made to plot the mean cell interior size and the mean wall thickness as a func- 

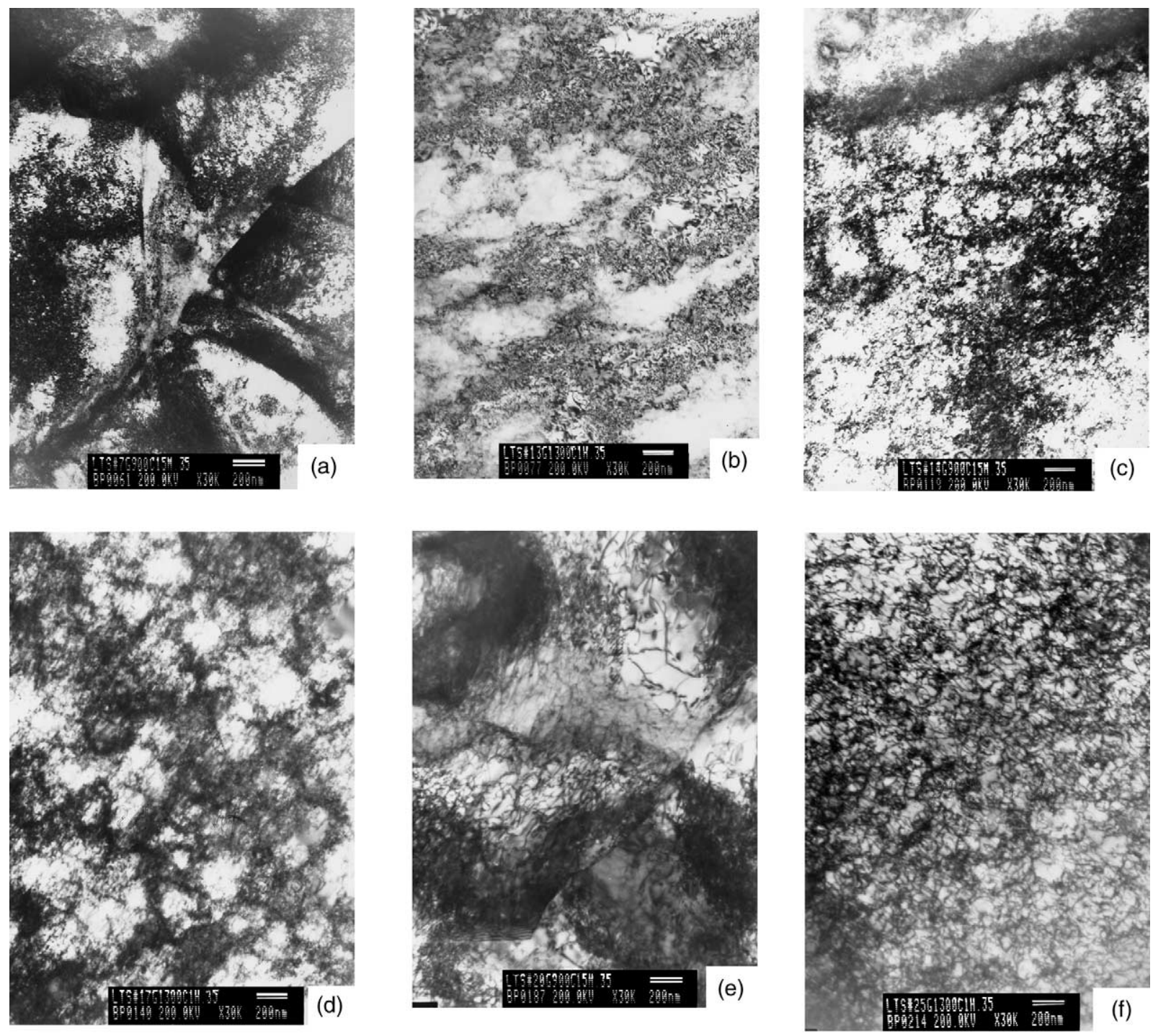

Fig. 3. Substructures developed in tensile specimens of the smallest $(3.1 \mu \mathrm{m}$; a,c,e) and largest $(86.7 \mu \mathrm{m}$; b,d,f) grain sizes upon deformation to $\varepsilon=0.34$ at three test temperatures of $297(\mathrm{a}, \mathrm{b}), 673(\mathrm{c}, \mathrm{d})$ and $973 \mathrm{~K}(\mathrm{e}, \mathrm{f})$. It is seen that the dislocations occupy large proportions of area, constituting thick cell walls. (High magnification).

tion of grain size but, as seen in Fig. 6(a), the scatter in the data does not suggest any definite relationship. However, in general the values of wall thickness are noted to be greater than the cell interior sizes. Further, the cell interior sizes and wall thickness were normalized by the grain size, and the same were plotted as a function of grain size. Irrespective of test temperatures, the normalized cell interior size $\left(\mathrm{d}_{\mathrm{ci}} / \mathrm{d}\right)$ and the normalized wall thickness $\left(\mathrm{d}_{\mathrm{w}} / \mathrm{d}\right)$ were found to decrease with the increase in grain size. Since the $\left(d_{c i} / d\right)$ data at different test temperatures were found to be overlapping, all these data were plotted together as a function of grain size in Fig. 6(b). Also included in this figure is the plot of normalized cell wall thickness as a function of grain size. The two curves are found to be identical except that the curve for $\left(d_{w} / d\right)$ is slightly above that for $\left(d_{c i} / d\right)$. 
(a)

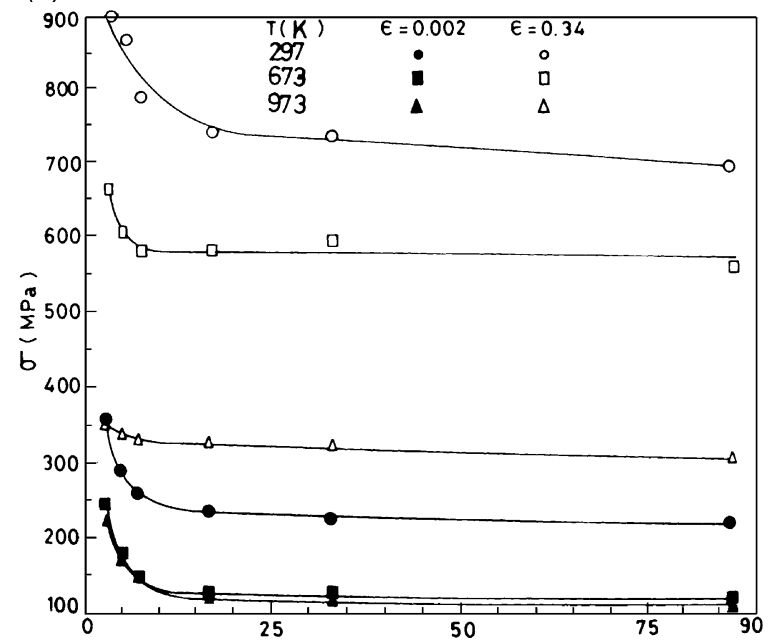

(b)

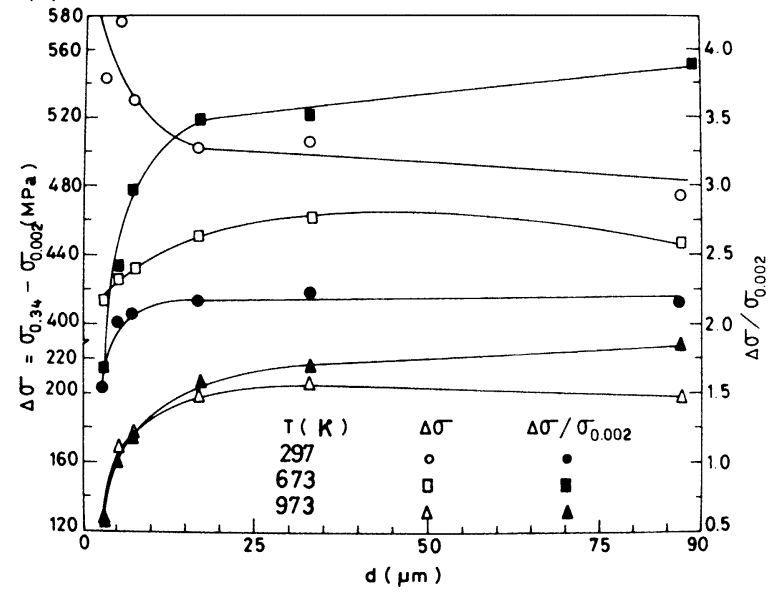

Fig. 4. Effect of grain size on: (a) flow stresses at yielding $(\varepsilon$ $=0.002$ ) and $\varepsilon=0.34$, (b) stress increment (flow hardening) $\Delta \sigma$ over a large strain (between $\varepsilon=0.002$ and $\varepsilon=0.34$ ) and the same normalized $\left(\Delta \sigma / \sigma_{0.002}\right)$ by yield stress. As expected, the flow stress decreases with increasing grain size but the extent and nature of flow hardening are sensitive to test temperature.

For both the normalized cell size and wall thickness, their variation with grain size could be represented by

$$
\begin{aligned}
& \left(d_{c i} / d\right)=0.275 d^{-1.04}\left(R^{2}=0.97\right) \\
& \left(d_{w} / d\right)=0.324 d^{-1.04}\left(R^{2}=0.95\right)
\end{aligned}
$$

where $R^{2}$ is the regression coefficient of the powerlaw fit of the data. Thus, although the cell size and wall thickness per se do not appear to be distinctly dependent on grain size (Fig. 6(a)), the normalized values of these substructural parameters are systematically sensitive to grain size, as brought out by Fig. 6(b). Therefore, the data in Fig. 6(a) are not truly scatter but they reflect somewhat systematic dependence of cell size and wall thickness on grain size, which could be delineated only by the type of plot given in Fig. 6(b). The above equation also reveals that the cell size and wall thickness, although poorly sensitive to grain size $\left(\mathrm{d}_{\mathrm{ci}} \propto \mathrm{d}^{-0.04}\right.$ and $\left.\mathrm{d}_{\mathrm{w}} \propto \mathrm{d}^{-0.04}\right)$, remain within a fixed size range of 0.15 to 0.50 .

Since the cell interior and the cell walls constitute microduplex-type or composite-like structure, an attempt was made to relate the cell interior size and wall thickness. A plot of normalized wall thickness as a function of normalized cell interior size is presented in Fig. 7. The interrelationship between the two can be expressed by the equations of type:

$d_{w} / d=m\left(d_{c i} / d\right)+c$

where $m$ is the slope and $c$ is the intercept of the straight line of the plot between $\left(\mathrm{d}_{\mathrm{w}} / \mathrm{d}\right)$ and $\left(\mathrm{d}_{\mathrm{ci}} / \mathrm{d}\right)$. The values of $m$ and $c$, along with the regression coefficient $\left(\mathrm{R}^{2}\right)$, at the three test temperatures investigated here are listed in Table 1 . It is noted that the sensitivity of the normalized wall thickness to the normalized cell size is maximum $(\mathrm{m}=1.79)$ at intermediate test temperature and minimum $(\mathrm{m}$ $=0.79$ ) at the highest test temperature of $973 \mathrm{~K}$. The values of intercepts in all the cases are nearly zero, which indicates that the cell interior size and the wall thickness are very small fractions of the grain size in the coarse-grained materials.

\subsection{Interrelation between flow hardening and cell parameters}

The normalized stress increment by deformation to $\varepsilon=0.34$, viz. $\left(\Delta \sigma / \sigma_{0.002}\right)$ was plotted as a function of normalized cell interior size $\left(\mathrm{d}_{\mathrm{ci}} / \mathrm{d}\right)$, normalized wall thickness $\left(\mathrm{d}_{\mathrm{w}} / \mathrm{d}\right)$, and the average of normalized cell interior size and normalized wall thickness as shown in Figs. 8, 9 and 10, respectively. It is seen that the normalized flow hardening decreases linearly with the increase in $\left(\mathrm{d}_{\mathrm{ci}} / \mathrm{d}\right)$ and 


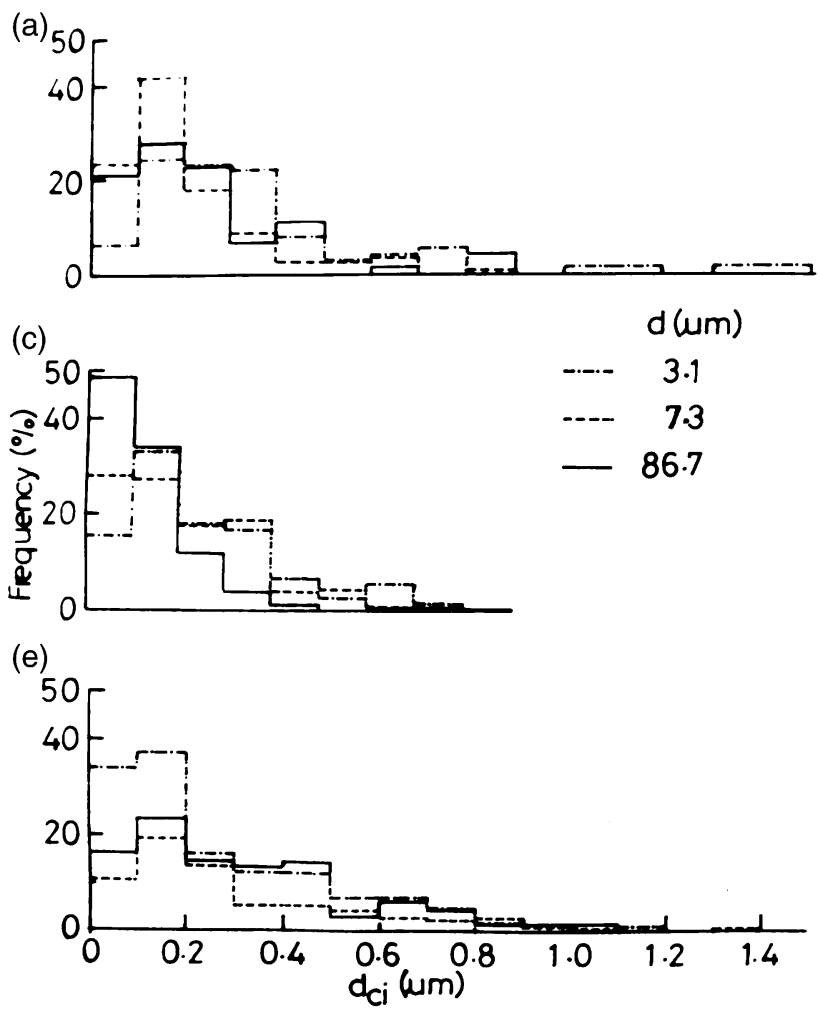

(b)

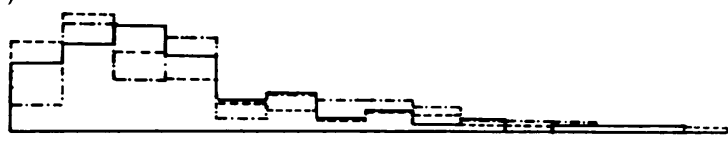

(d)

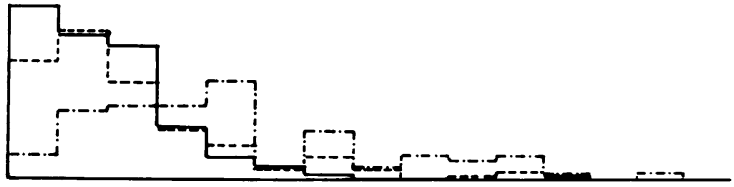

(f)

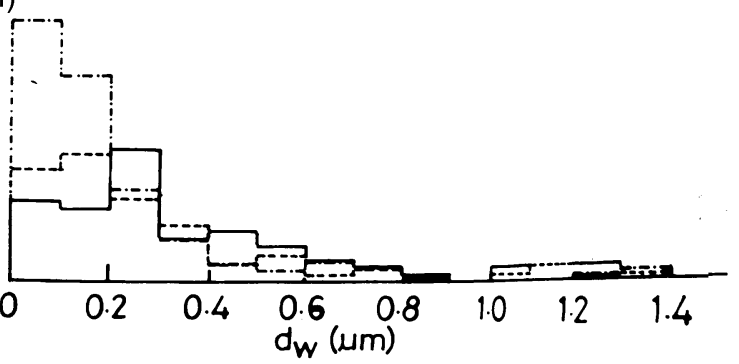

Fig. 5. Histograms of cell interior size (a,c,e) and cell wall thickness (b,d,f) for the specimens of different grain sizes deformed to $\varepsilon=0.34$ at test temperatures of $297 \mathrm{~K}(\mathrm{a}, \mathrm{b}), 673 \mathrm{~K}(\mathrm{c}, \mathrm{d})$ and $973 \mathrm{~K}(\mathrm{e}, \mathrm{f})$. Higher frequencies are seen towards the finer sizes of cell interior and cell wall.

$\left(\mathrm{d}_{\mathrm{w}} / \mathrm{d}\right)$. Thus, the relationship between $\left(\Delta \sigma / \sigma_{0.002}\right)$ and $\left(\mathrm{d}_{\mathrm{c}} / \mathrm{d}\right)$, between $\left(\Delta \sigma / \sigma_{0.002}\right)$ and $\left(\mathrm{d}_{\mathrm{w}} / \mathrm{d}\right)$, and between $\left(\Delta \sigma / \sigma_{0.002}\right)$ and $\left(\left(\mathrm{d}_{\mathrm{ci}}+\mathrm{d}_{\mathrm{w}}\right) / \mathrm{d}\right)$ can be written as

$$
\begin{aligned}
& \left(\Delta \sigma / \sigma_{0.002}\right)=-m^{\prime}\left(d_{c i} / d\right)+c^{\prime} \\
& \left(\Delta \sigma / \sigma_{0.002}\right)=-\mathrm{m}^{\prime \prime}\left(d_{w} / d\right)+\mathrm{c}^{\prime \prime} \\
& \left(\Delta \sigma / \sigma_{0.002}\right)=-m^{\prime}{ }^{\prime \prime}\left(\left(d_{c i}+d_{w}\right) / d\right)+c^{\prime}{ }^{\prime \prime}
\end{aligned}
$$

with the values of slopes (m', m" and m'") and intercepts (c', c" and c'") listed in Table 2, along with the values of regression coefficients $R^{2}$. It is found that the sensitivity of normalized flow hardening on normalized cell size (m') is highest at the intermediate test temperature whereas the highest sensitivity of normalized flow hardening on normalized wall thickness (m") exists at the highest test temperature of $973 \mathrm{~K}$. The ratio of the maximum to the minimum values of $m$ ' is found to be 4.1 and the same for $\mathrm{m}$ " is found to be 3.9.

\section{Discussion}

The decreases in yield stress and flow stress at $\varepsilon=0.34$ with the increase in grain size, as seen in Fig. 4(a), were found [6] to follow the H-P-type relationship [1,2], viz.

$\sigma(\varepsilon)=\sigma_{o}(\varepsilon)+k(\varepsilon) d^{-0.5}$

The values of friction stress $\left(\sigma_{\mathrm{o}}\right)$ and the H-P slope $\mathrm{k}$ at $\varepsilon=0.002$ and 0.34 are listed in Table 3 .

While the first part on the right hand side $\left(\sigma_{\mathrm{o}}\right)$ of eq. (4) represents the friction stress in the grain interior, the second part $\mathrm{k}(\varepsilon) \mathrm{d}^{-0.5}$ represents the stress component for the given grain size due to 


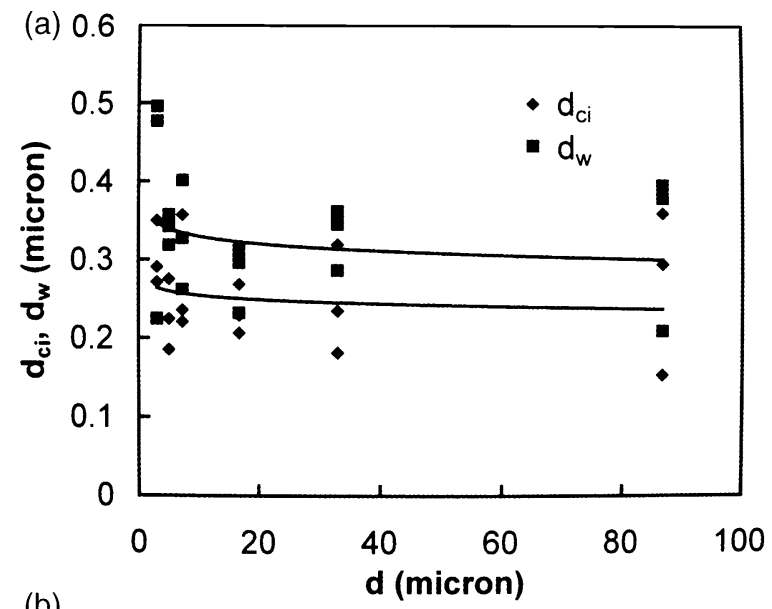

(b)

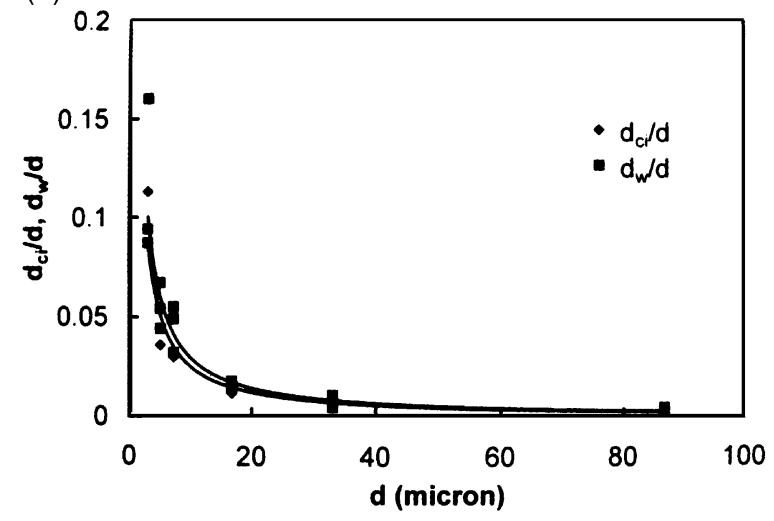

Fig. 6. Plot of (a) cell interior size $\left(\mathrm{d}_{\mathrm{ci}}\right)$ and wall thickness $\left(d_{w}\right),(b)$ normalized cell interior size $\left(d_{c i} / d\right)$ and normalized cell wall thickness $\left(d_{w} / d\right)$ as a function of grain size (d) at three test temperatures. In general, $d_{w}$ is greater than $d_{c i}$. The two appear as scatter in relation to grain size but, when plotted in a normalized form, a systematic dependence on grain size emerges.

grain boundary resistance. The $\mathrm{H}-\mathrm{P}$ parameters, based on the yield stress values for different grain sizes, denote the effect of initial microstructures, including the contribution of dislocations over the microyielding range. The same upon deformation to the strain of 0.34 will further include the effect of substuctural changes. The ratio of the flow stress increment $\Delta \sigma$ at $\varepsilon=0.34$ to that at yield is found to increase with grain size (Fig. 7(b)), which reflects that the work hardening rate $(\Delta \sigma$ divided by $\Delta \varepsilon=0.34-0.002)$ in the grain interior is more than that in the grain boundary region. The values of $\sigma_{\mathrm{o}, 0.34} / \sigma_{\mathrm{o}, 0.002}$ in Table 3 ranges between 4 and 7 whereas $\mathrm{k}_{0.34} / \mathrm{k}_{0.002}$ ranges between 0.3 and 1.6.

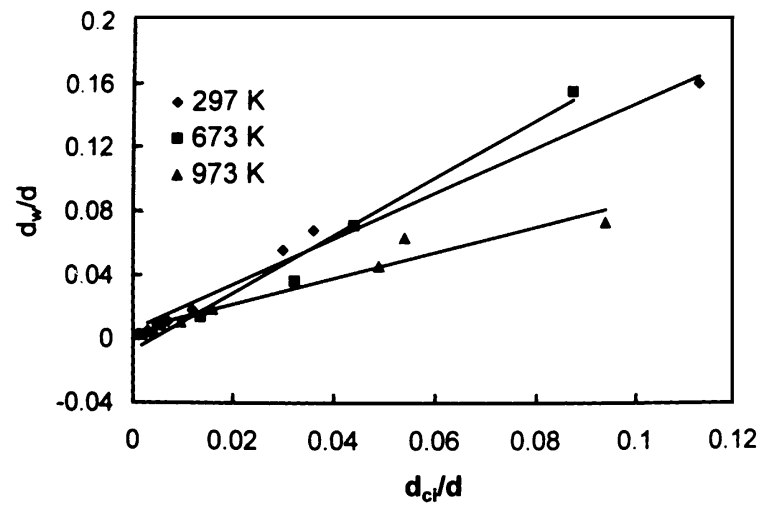

Fig. 7. Plot of normalized cell wall thickness $\left(d_{w} / d\right)$ as a function of normalized cell interior size $\left(\mathrm{d}_{\mathrm{c}} / \mathrm{d}\right)$ at three test temperatures. The two cell parameters are interrelated.

Table 1

Values of $\mathrm{m}, \mathrm{c}$ and $\mathrm{R}^{2}$ of the straight lines (eq. (2)) relating $\left(\mathrm{d}_{\mathrm{w}} / \mathrm{d}\right)$ and $\left(\mathrm{d}_{\mathrm{ci}} / \mathrm{d}\right)$ at different test temperatures

\begin{tabular}{llrl}
\hline $\mathrm{T}(\mathrm{K})$ & $\mathrm{m}$ & $\mathrm{c}$ & $\mathrm{R}^{2}$ \\
\hline 297 & 1.41 & $5.5 \times 10^{-3}$ & 0.99 \\
673 & 1.79 & $-7.3 \times 10^{-3}$ & 0.98 \\
973 & 0.79 & $5.4 \times 10^{-3}$ & 0.93 \\
\hline
\end{tabular}

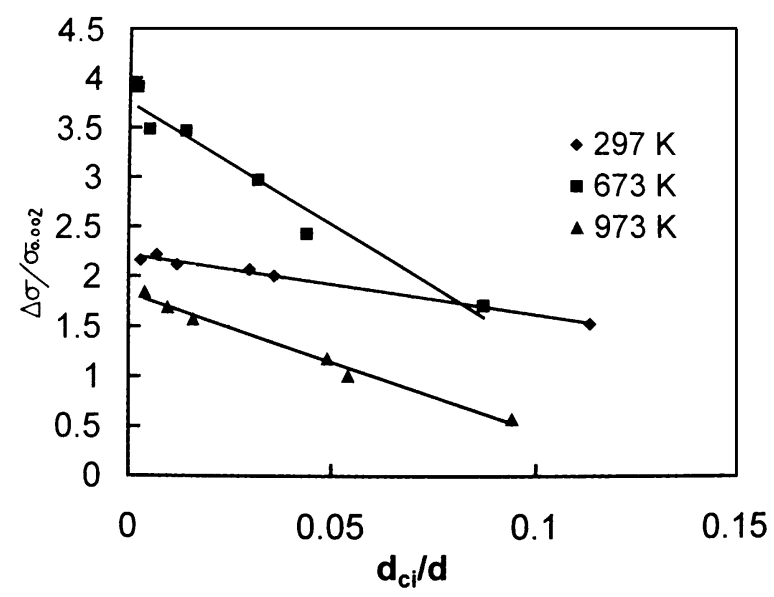

Fig. 8. Variation in normalized stress increment $\left(\Delta \sigma / \sigma_{0.002}\right)$ as a function of normalized cell interior size $\left(\mathrm{d}_{\mathrm{ci}} / \mathrm{d}\right)$ at three test temperatures. The maximum sensitivity of the property on structure is obtained at the temperature $(673 \mathrm{~K})$ of dynamic strain aging. 


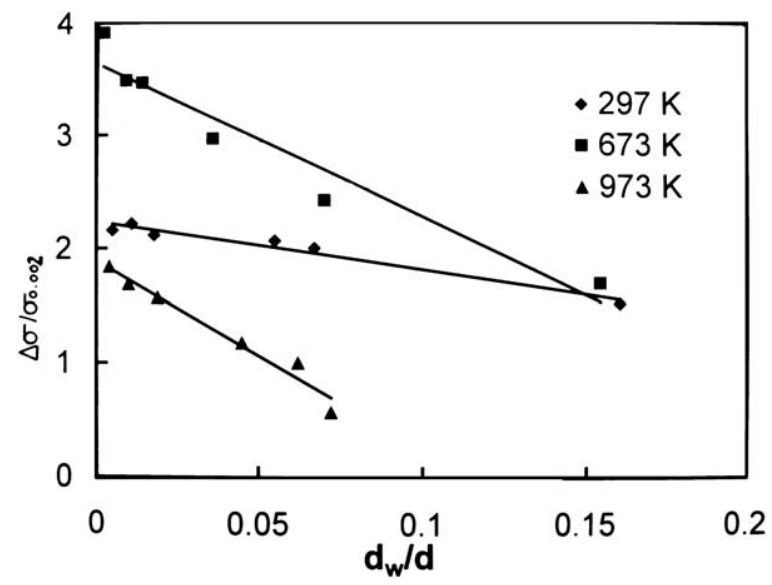

Fig. 9. Variation in normalized stress increment $\left(\Delta \sigma / \sigma_{0.002}\right)$ as a function of normalized cell wall thickness $\left(\mathrm{d}_{\mathrm{w}} / \mathrm{d}\right)$ at three test temperatures. The maximum sensitivity of the property on structure is obtained at the temperature $(673 \mathrm{~K})$ of dynamic strain aging.

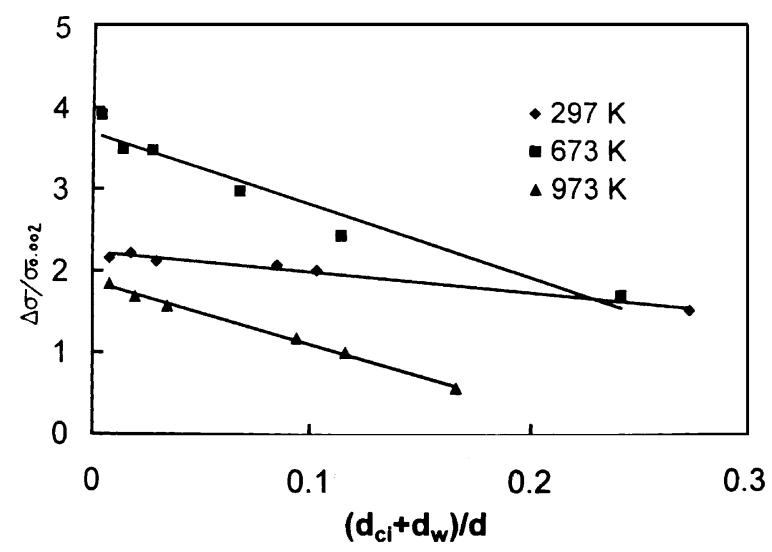

Fig. 10. Variation in normalized stress increment $\left(\Delta \sigma / \sigma_{0.002}\right)$ as a function of normalized cell wall thickness and cell interior size combined $\left(\left(\mathrm{d}_{\mathrm{ci}}+\mathrm{d}_{\mathrm{w}}\right) / \mathrm{d}\right)$ at three test temperatures. The maximum sensitivity of the property on structure is obtained at the temperature $(673 \mathrm{~K})$ of dynamic strain aging.

The highest values of $\Delta \sigma / \sigma_{0.002}$ at $673 \mathrm{~K}$, rather than at $297 \mathrm{~K}$, can be attributed to the enhanced dislocation density due to dynamic strain aging $[5,6]$ at this temperature, which is seen in the form of the highest frequency of the finer cell interior sizes (Fig. 5(c)). In the absence of work hardening, there does not appear any significant difference in the effect of grain size on yield stress at 673 and 973 K (Fig. 4(a)). The anomaly of the comparable
Table 2

Values of slopes (m', m", m'"), intercepts (c', c", c"') and regression coefficients $\left(\mathrm{R}^{2}\right)$ according to eqs. ( $3 \mathrm{a}, \mathrm{b}$ and $\mathrm{c}$ )

\begin{tabular}{llrr}
\hline Parameters & $\begin{array}{l}\mathrm{T}(\mathrm{K}) \\
297\end{array}$ & 673 & 973 \\
\hline Eq. (3a) & & & \\
m' & 6.08 & 24.96 & 13.83 \\
c' & 2.22 & 3.75 & 1.83 \\
R & 0.98 & 0.96 & 0.99 \\
Eq. (3b) & & & \\
m” & 4.24 & 13.64 & 16.63 \\
c" & 2.23 & 3.64 & 1.89 \\
R & 0.96 & 0.93 & 0.97 \\
Eq. (3c) & & & \\
m”, & 2.51 & 8.86 & 7.69 \\
c"” & 2.23 & 3.68 & 7.70 \\
R & 0.97 & 0.95 & 1.00 \\
\hline
\end{tabular}

Table 3

Values of the Hall-Petch parameters, $\sigma_{\mathrm{o}}(\mathrm{MPa})$ and $\mathrm{k}(\mathrm{MPa}$ $\left.\mu \mathrm{m}^{-0.5}\right)$ at yielding and at the terminal strain at the three test temperatures

\begin{tabular}{lrrr}
\hline H-P Parameters & $\begin{array}{l}\text { T }(\mathrm{K}) \\
\text { 297 }\end{array}$ & \multicolumn{1}{c}{673} & \multicolumn{1}{c}{973} \\
\hline$\sigma_{\mathrm{o}}(\varepsilon=0.002)$ & 175.67 & 76.82 & 75.38 \\
$\mathrm{k}(\varepsilon=0.002)$ & 279.95 & 252.96 & 232.19 \\
$\sigma_{\mathrm{o}}(\varepsilon=0.34)$ & 641.87 & 543.10 & 303.29 \\
$\mathrm{k}(\varepsilon=0.34)$ & 455.52 & 163.53 & 76.26 \\
$\sigma_{\mathrm{o}, 0.34} / \sigma_{\mathrm{o}, 0.002}$ & 3.65 & 7.07 & 4.02 \\
$\mathrm{k}_{0.34} / \mathrm{k}_{0.002}$ & 1.63 & 0.65 & 0.33 \\
\hline
\end{tabular}

levels of yield stress at these two temperatures emerges from the two opposing effects. As reported earlier [5], the temperature of $673 \mathrm{~K}$ is noted to be an intermediate temperature in the range of the dominance of dynamic strain aging, whereas the temperature of $973 \mathrm{~K}$ falls in the transition between athermal and high-temperature regions of the stress vs temperature plot. It is a coincidence of temperatures taken here that the increasing stress due to dynamic strain aging becomes equal to the decreasing stress due to thermally activated process.

It is interesting that the flow stress increment between yield point and the strain of 0.34 , viz. $\Delta \sigma$ $=\sigma_{0.34}-\sigma_{0.002}$, decreases with the increase in grain size at $297 \mathrm{~K}$ but the same increases with grain 
size at the higher temperatures. This behavior can be explained by the strain hardening in the grain interior and grain boundary regions as follows.

The values of $\Delta \sigma=\sigma_{0.34}-\sigma_{0.002}$ were obtained from the stress values at $\varepsilon=0.34$ and $\varepsilon=0.002$. Each of these stresses is contributed by the strengths of grain interior $\left(\sigma_{\mathrm{o}}\right)$ and grain boundaries $(\mathrm{k})$, with the proportion of the latter changing with grain size $\left(\mathrm{kd}^{-0.5}\right)$. Thus, $\Delta \sigma$ will also have two components of increment - one due to grain interior $\left(\Delta \sigma_{\mathrm{o}}\right)$ and the other due to grain boundaries $(\Delta \mathrm{k})$. The contributions of grain interior and grain boundaries are encompassed in the H-P-type relationship; and so $\Delta \sigma$ can be expressed as

$\Delta \sigma=\Delta \sigma_{o}+\Delta k d^{-0.5}$

Here $\Delta \sigma_{\mathrm{o}}$ and $\Delta \mathrm{k}$ are the differences in the values of $\sigma_{\mathrm{o}}$ and $\mathrm{k}$ between $\varepsilon=0.34$ and $\varepsilon=0.002$. The ratio of the increase in the strengths of grain interior between these two strains $\left(\Delta \sigma_{\mathrm{o}}\right)$ to $\sigma_{\mathrm{o}}$ at yield (i.e., $\Delta \sigma_{\mathrm{o}} / \sigma_{\mathrm{oy}}$ ) were determined to be 2.65 , 6.07 and 3.02 at $\mathrm{T}=297,673$ and $973 \mathrm{~K}$, respectively. The corresponding ratios of the $\mathrm{H}-\mathrm{P}$ slope (i.e., $\Delta \mathrm{k} / \mathrm{k}_{\mathrm{y}}$ ) were determined to be $0.63,-0.35$ and -0.67 , at the respective temperatures. This reveals that whereas the increment in grain boundary-strengthening $\Delta \mathrm{k} / \mathrm{k}_{\mathrm{y}}$ is positive of magnitude 0.63 at the temperature of $297 \mathrm{~K}$, there occurs relative grain boundary softening at the higher temperatures. Therefore, the decreasing volume fraction of grain boundary area with the increasing grain size leads to a decrease in the contribution of grain boundary-strengthening component to $\Delta \sigma$. Perhaps this is the reason that $\Delta \sigma$ decreases with the increase in grain size, as seen at $\mathrm{T}=297 \mathrm{~K}$ in Fig. 4(b). On the basis of similar consideration, the negative values of $\Delta \mathrm{k} / \mathrm{k}_{\mathrm{y}}$ at $\mathrm{T}=673$ and $973 \mathrm{~K}$ lead to the increase in $\Delta \sigma$ with grain size. Unlike the nature of the variation in $\Delta \sigma$ emerging predominantly from the role of grain boundaries, the variation in $\Delta \sigma / \sigma_{0.002}$ is dominated by the substructural changes that occur in the grain interior. This is because of the fact that $\sigma_{0.002}$ includes the primary effect of the difference in grain sizes, and the numerator $\Delta \sigma$ subscribes to the flow stress beyond the direct effect of grain size.

Knowing the values of the H-P parameters $\sigma_{\mathrm{o}}$ and $\mathrm{k}$ as given in Table 3 at $\varepsilon=0.34$ and $\varepsilon=0.002$, and by taking their differences between these two strains, the contributions to strengthening by grain interior $\left(\Delta \sigma_{\mathrm{o}}\right)$ and grain boundaries $\left(\Delta \mathrm{k} \mathrm{d}^{-0.5}\right)$ were determined according to eq. (5). Although the differences in the magnitudes of the $\mathrm{H}-\mathrm{P}$ parameters $\left(\Delta \sigma_{\mathrm{o}}\right)$ and $(\Delta \mathrm{k})$ are constant at a given temperature, the relative contributions to strengthening by grain interior $\left(\Delta \sigma_{\mathrm{o}}\right)$ and grain boundaries $\left(\Delta \mathrm{k} \mathrm{d}^{-0.5}\right)$ vary as a function of grain size. Plotted in Fig. 11(a-c), as a function of grain size, is the ratio of the increments in the strengthening caused by grain interior to grain boundaries on the strain increment of 0.34-0.002. Also included is such a plot at the yield point. It is seen that with the increasing grain size, plastic deformation to $\varepsilon=0.34$ results in a greater increment of grain interior strengthening than the grain boundary strengthening, with the ratio $\left(\Delta \sigma_{\mathrm{o}} / \Delta \mathrm{k} \mathrm{d}^{-0.5}\right)$ increasing from 4.7 for $\mathrm{d}=3.1$ $\mu \mathrm{m}$ to 24.7 for $\mathrm{d}=86.7 \mu \mathrm{m}$ at $\mathrm{T}=297 \mathrm{~K}$. The relative increase in strengthening by a factor of $24.7 / 4.7=5.3$ is related to the grain sizes $\left(d_{1}\right.$ and $d_{2}$ ) by $(3.1 / 86.7)^{-0.5}$ or $\left(d_{1} / d_{2}\right)^{-0.5}$. Since the ratio of the increment of grain interior strengthening to grain boundary strengthening depends on grain size alone at a given temperature, the same ratio of 5.3 for the smallest and the largest grain sizes investigated here is obtained at other test temperatures of 673 and $973 \mathrm{~K}$. However, the magnitudes of $\left(\Delta \sigma_{\mathrm{o}} / \Delta \mathrm{k} \mathrm{d}^{-0.5}\right)$ themselves vary with temperature through the temperature sensitivity of the H-P parameters. The plot of $\sigma_{\mathrm{oy}} / \mathrm{k}_{\mathrm{y}}$ at yield as a function of grain size also leads to a similar conclusion. It may be also noted that the negative values of $\Delta \mathrm{k}$ at 673 and $973 \mathrm{~K}$ result in an inverse dependence on grain size of the relative grain interior to grain boundary strengthening $\left(\Delta \sigma_{\mathrm{o}} / \Delta \mathrm{k} \mathrm{d}^{-0.5}\right)$.

The plot of normalized stress increment $\Delta \sigma / \sigma_{0.002}$ as a function of normalized cell interior size $\mathrm{d}_{\mathrm{ci}} / \mathrm{d}$ (Fig. 8), normalized wall thickness $\mathrm{d}_{\mathrm{w}} / \mathrm{d}$ (Fig. 9) and the average cell parameter $\left(\left(d_{c i}+\right.\right.$ $\mathrm{d}_{\mathrm{w}}$ )/2) (Fig. 10) supports the common fact that the refinement in substructure increases the strength of materials. The maximum sensitivity of normalized stress increment on structural parameter seen at $673 \mathrm{~K}$ may be due to the further effect of dynamic strain aging. An attempt was made to explore the source of relative contributions to strengthening $\left(\Delta \sigma_{\mathrm{o}} / \Delta \mathrm{k} \mathrm{d}^{-0.5}\right)$ in terms of substructures and grain 

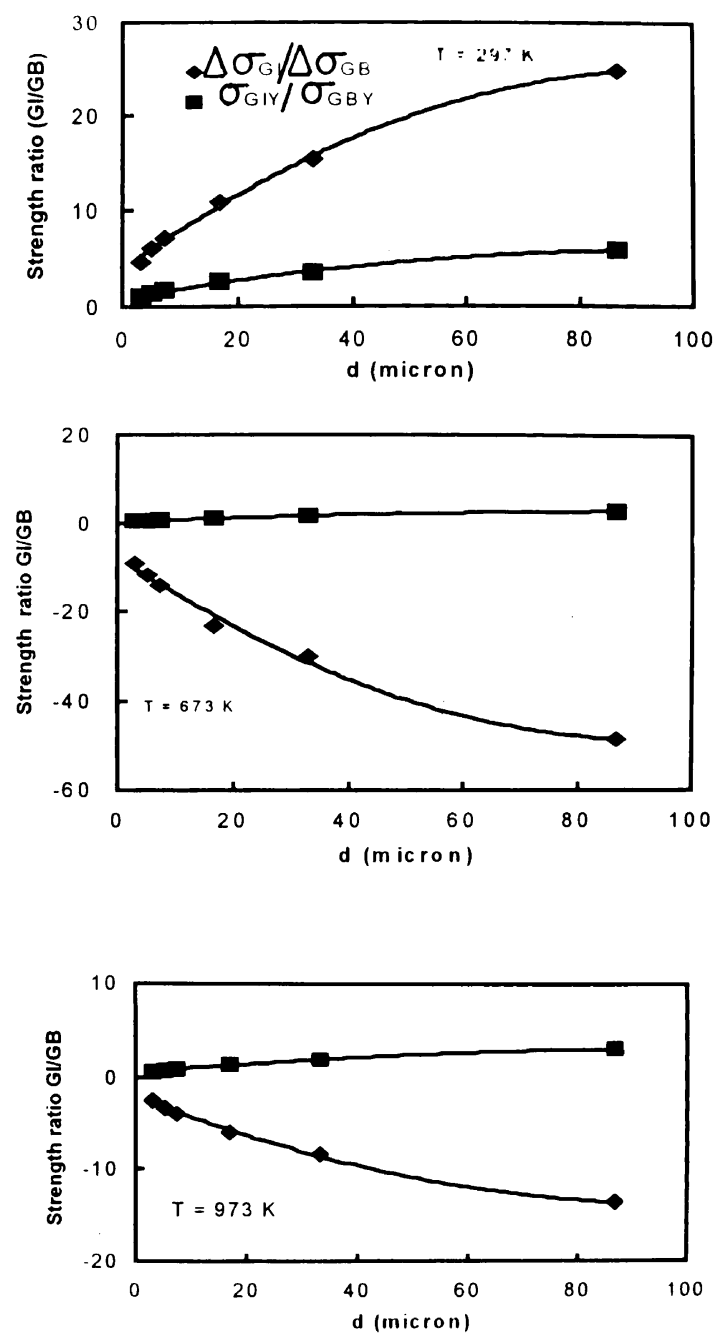

Fig. 11. Ratio of the strengthening contributions of grain interior to grain boundaries $\left(\Delta \sigma_{\mathrm{o}} / \Delta \mathrm{k} \mathrm{d}^{-0.5}\right.$ being denoted by $\Delta \sigma_{\mathrm{GI}} / \Delta \sigma_{\mathrm{GB}}$ here) on strain increment of $0.34-0.002$ plotted as a function of grain size at three test temperatures (T, K): (a) 297 , (b) 673 , (c) 973 . Also plotted is the ratio of the strength of grain interior to grain boundaries at yield point $\left(\sigma_{\text {oy }} /\left(\mathrm{k}_{\mathrm{y}} \mathrm{d}^{-}\right.\right.$ $\left.{ }^{0.5}\right)$, being denoted by $\sigma_{\mathrm{GIY}} / \sigma_{\mathrm{GBY}}$ here). Whereas at $297 \mathrm{~K}$, $\left(\Delta \sigma_{\mathrm{o}} /\left(\Delta \mathrm{k} \mathrm{d}^{-0.5}\right)\right)$ is positive and increases with grain size, at other temperatures, the same decreases with increase in grain size. The difference between the two curves also increases with grain size. size. Since no cells were formed at yielding, the stress increment upon deformation to the strain of 0.34 should be related to the dimensions of cell interior and cell wall that developed by this strain increment. However, $\Delta \sigma_{\mathrm{o}}$, obtained from the difference in the H-P parameter $\sigma_{\mathrm{o}}$ at the two strains and so also $\Delta \mathrm{k}$, do not depend on grain size but the relative contributions of grain interior and grain boundary strengthening depend on grain size. The increase in $\left(\Delta \sigma_{\mathrm{o}} / \Delta \mathrm{k} \mathrm{d}^{-0.5}\right)$ with grain size should, therefore, be attributed to some substructural parameters. Fig. 12 shows a plot of $\left(\Delta \sigma_{\mathrm{o}} / \Delta \mathrm{k} \mathrm{d}^{-0.5}\right)$ as a function of normalized cell parameter $\left(\mathrm{d}_{\mathrm{ci}}+\mathrm{d}_{\mathrm{w}}\right) / \mathrm{d}$, following a logarithmic relationship as given below.

$$
\left(\Delta \sigma_{o} / \Delta k d^{-0.5}\right)=m_{1} \ln \left(\left(d_{c i}+d_{w}\right) / d\right)+c_{1}
$$

The values of $\mathrm{m}_{1}$ and $\mathrm{c}_{1}$ at the test temperatures investigated are listed in Table 4 . It is found that $\left(\Delta \sigma_{\mathrm{o}} / \Delta \mathrm{k} \mathrm{d}^{-0.5}\right)$ decreases with increasing $\left(\mathrm{d}_{\mathrm{ci}}+\right.$ $\left.\mathrm{d}_{\mathrm{w}}\right) / \mathrm{d}$ at $\mathrm{T}=297 \mathrm{~K}$ but, at other test temperatures, the reverse is true. It is also interesting to note from Fig. 12 that the curves at different temperatures tend to approach a similar value of $\left(\Delta \sigma_{\mathrm{o}} / \Delta \mathrm{k} \mathrm{d}^{-0.5}\right)$ towards the larger $\left(\mathrm{d}_{\mathrm{ci}}+\mathrm{d}_{\mathrm{w}}\right) / \mathrm{d}$, in spite of the initially large difference in the nature of curves at different temperatures. The earlier TEM studies

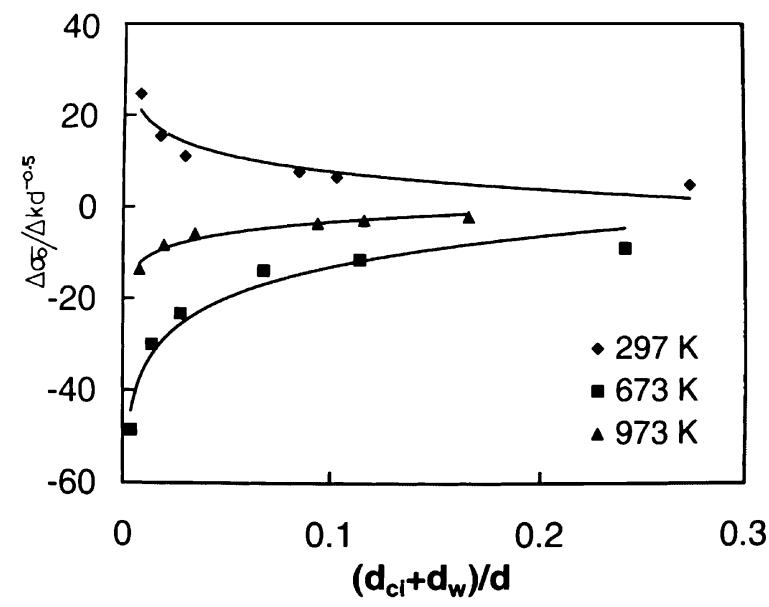

Fig. 12. Plot of relative contributions of grain interior and grain boundary strengthening $\left(\Delta \sigma_{\mathrm{o}} /\left(\Delta \mathrm{k} \mathrm{d}^{-0.5}\right)\right)$, upon straining from yield point to $\varepsilon=0.34$, as a function of normalized cell interior size and wall thickness combined $\left(\left(\mathrm{d}_{\mathrm{ci}}+\mathrm{d}_{\mathrm{w}}\right) / \mathrm{d}\right)$ at three test temperatures. The curves exhibit negative slopes at $297 \mathrm{~K}$ and positive slopes at higher test temperatures. 
Table 4

Values of $\mathrm{m}_{1}, \mathrm{c}_{1}$ and $\mathrm{R}^{2}$ in eq. (6) at different test temperatures

\begin{tabular}{llll}
\hline Parameters & $\begin{array}{l}\mathrm{T}(\mathrm{K}) \\
297\end{array}$ & 673 & 973 \\
\hline $\mathrm{m}_{1}$ & -5.49 & 9.69 & 3.47 \\
$\mathrm{c}_{1}$ & -5.36 & 8.91 & 4.32 \\
$\mathrm{R}^{2}$ & 0.88 & 0.95 & 0.95 \\
\hline
\end{tabular}

[5,6] on substructural evolution in this material revealed at small strains a distinct structure near the grain boundaries and in the grain interior depending on test temperature. At ambient temperature, the dislocations were confined to the vicinity of the grain boundary, at intermediate temperatures the dislocations were spread into the grain interior and at high temperatures the dislocations rearranged to form walls. In spite of the very high dislocation densities developed upon deformation to the large strain of 0.34, Figs. 2 and 3 , a somewhat similar trend appears to have prevailed. For example, at 297 K (Fig. 2(a,b) and $3(a, b))$, the alternate dislocation-rich and dislocation-lean zones are found to constitute a carpettype structure, possibly the grain boundary vicinity still possessing the first layer of high dislocation density formed. As the dislocation density increases rapidly in the grain interior at $673 \mathrm{~K}$, due to dynamic strain aging, the stress at this temperature may reach a critically high value to facilitate cross-slip, thus making the stress and thermal combination conducive to cell formation by dynamic recovery process (Fig. 2(c,d) and 3(c,d)). At 973 $\mathrm{K}$, it may be expected that the grain boundaries will have a tendency to act as a sink for dislocations once the critical dislocation density for dynamic recovery at this temperature is reached. Therefore, at this temperature the cells are not likely to form in the grain boundary vicinity but, instead, may form in the grain interior. It might be also possible that at the strains used here $(\varepsilon=0.34)$, the cell walls may start becoming the sites for dynamic recovery, making the cell-wall strengthening less effective. The effect of such structural evolution is also reflected in the nature of the stress-strain curves in Fig. 1, which reveal an increasing tendency for dynamic recovery as the test temperature is increased. Such may be the reason that the nature of the $\left(\Delta \sigma_{\mathrm{o}} / \Delta \mathrm{k} \mathrm{d}^{-0.5}\right) v s\left(\mathrm{~d}_{\mathrm{ci}}+\right.$ $\left.\mathrm{d}_{\mathrm{w}}\right) / \mathrm{d}$ plots is different at different test temperatures. In Fig. 12, the increasing contribution of grain interior strengthening with increasing cell dimensions may be due to higher dislocation density developed in the grain interior, rather than in the grain boundary vicinity, at $\mathrm{T}=673$ and $973 \mathrm{~K}$. On the other hand, the decreasing contribution at $297 \mathrm{~K}$ may be due to the relatively higher dislocation density in the vicinity of grain boundaries and lower dislocation density in the grain interior [5]. This is in conformity with the higher dislocation density in the grain interior under dynamic strain aging conditions at $673 \mathrm{~K}$, and higher dislocation density or smaller cell sizes in the vicinity of grain boundaries at $297 \mathrm{~K} \mathrm{[6].}$

During plastic deformation at low temperatures, the strain in the polycrystalline material is achieved through the movement of dislocations, whose density also increases in the course of deformation. However, the same dislocations make the subsequent deformation more difficult. The grain boundaries provide resistance to movement of dislocations and hence the latter accumulate until their density becomes large enough to penetrate through the grain boundaries or activate some other dislocation sources in their vicinity [10]. The increase in dislocations near the grain boundary, known as geometrically necessary dislocations [11], provides compatibility between adjoining grains. Upon deformation to a large strain such as $\varepsilon=0.34$ used here, the higher dislocation density in the vicinity of grain boundaries $\left(\rho_{\mathrm{g}}\right)$ results in smaller cells near the grain boundaries and the lower dislocation density $\left(\rho_{\mathrm{s}}\right)$ in the grain interior, called statistically stored dislocations [11], results in larger cells. Such a gradient of increasing cell size from the grain boundary towards the grain interior was reported [6] in the fine-grained materials deformed at $297 \mathrm{~K}$. However, in the beginning of deformation at $\mathrm{T}=973 \mathrm{~K}$, the grain boundary vicinity was noticed [12] to be rather free from dislocations, with no sign of dislocation pile-ups. The increase in dislocation density during deformation results in an increase in stored energy of the materials. Based on the values of $\rho_{g}$ and $\rho_{s}$, there will also be a gradient in stored energy, suggesting 
a higher value in the vicinity of the grain boundary at $\mathrm{T}=297 \mathrm{~K}$ and a lower value at $973 \mathrm{~K}$. The total stored energy $\left(\mathrm{E}_{\mathrm{T}}\right)$ is given by $[13,14]$

$$
\begin{aligned}
E_{T} & =E_{s}+E_{g}=\alpha G b^{2}\left(\rho_{s}+\rho_{g}\right)=E_{s} \\
& +K_{1} d^{-1}
\end{aligned}
$$

where $\mathrm{E}$ is the stored energy and subscripts $\mathrm{s}$ and $\mathrm{g}$ represent statistically stored and geometrically necessary components respectively, $\alpha$ (depending on the interaction between dislocations) and $\mathrm{K}_{1}$ are constants and $\mathrm{G}$ and $\mathrm{b}$ have their usual meanings. According to eq. (7), the smaller-grained materials will have higher stored energy and, $\rho_{g}$ being greater than $\rho_{\mathrm{s}}$ at $\mathrm{T}=297 \mathrm{~K}, \mathrm{E}_{\mathrm{g}}$ will also be greater than $E_{s}$. The higher dislocation density, $\rho_{g}$, resulting in a greater value of $E_{g}$, will thus form smaller cells. The relationship between cell size and dislocation density is given by $[15,16]$ :

$d_{c}=K / \rho_{t}^{0.5}$

where $\rho_{\mathrm{t}}$ is total dislocation density and $\mathrm{K}$ is a constant. According to the hypothesis of low-energy dislocation structure [17], those structures in equilibrium with the applied tractions are formed which most nearly minimize the stored energy. The local variation in cell size, in turn, influences the stress distribution $\left(\tau \propto 1 / \mathrm{d}_{\mathrm{c}}, \tau\right.$ being the shear stress) and, therefore, the structural gradient once evolved may persist following the principle of similitude [1719]. As such, increasing the stress by a factor of $\mathrm{n}$ will shrink the scale of the structure by the factor $1 / \mathrm{n}$ without altering the nature of its geometry. The larger dimension of wall thickness to cell interior, seen in Fig. 6(a), may be attributed to the continued dislocation gradient first at the grain boundaries, then at the first- and higher-order cell walls. The comparison of cell-wall and cell-interior size developed at different temperatures also revealed that at $973 \mathrm{~K}$ the cell-interior sizes were larger than the cell-wall thickness. This is suggested to be due to the annihilation of dislocations at the cell walls, as happened at grain boundaries for the small strain levels [12]. The separation of cell-interior and cellwall dimensions shows them to decrease with the increase in grain size but none of them are found to follow the type of grain-size dependence given in eq. (7). However, this supports another fact that the formation of cell structure is only slightly dependent on the original grain size [20]. The plot of normalized cell parameters $\left(\mathrm{d}_{\mathrm{ci}} / \mathrm{d}\right.$ and $\left.\mathrm{d}_{\mathrm{w}} / \mathrm{d}\right)$ as a function of grain size, on the other hand, reveals a definite trend. This leads to a suggestion that the nature of substructural evolution rather than the substructure per se is sensitive to grain size; similar to that $d \sigma$ (or the work-hardening rate $d \sigma / d \varepsilon$ ) is more appropriate than $\sigma$ in understanding the flow mechanism [21].

The mechanisms of cell formation and partitioning of dislocations between cell interior and cell walls are still the subject of research [22,23]. Zaiser et al. [23] summarized that dislocation cell formation is representative of non-equilibrium system where "entropy wins over energy" [24], rather than being guided by the evolution of "low-energy dislocation structures" [25]. Generally, the dislocations seen upon large strain deformation are of mixed type. The higher stored energy due to generation of dislocations during deformation is reduced by cross-slip of groups of dislocations, which produce relaxed dislocation structures. Whereas the screw components of the dislocations coming from the oppositely located dislocation sources get annihilated in the cell interior, their edge components get plated to form cell walls [7,22], leading to a higher dislocation density in the cell wall. However, it should be pointed out here that the character of dislocations in the cell wall may not remain simply of the edge type when multiple slip occurs. On the basis of the higher dislocation density in the cell wall than that in the cell interior, in type 316 stainless steel [26], the cell walls were shown to be about twice as strong as the cell interiors. In Fig. 7, it is seen that both the wall thickness and the cell interior size are interrelated. This is probably the reason that the strength increment by straining to $34 \%$ can be related well to any of the cell parameters (Figs. 8-10) here. However, the measurement of dislocation densities in the cell interior and cell walls would give better insight about their relative contributions to deformation. In the absence of such data, it is reasonable to assume that the strength of the cell wall is twice the strength of the cell interior, as it was analyzed to be the case in the 316 stainless steel [26]. Whereas at the yield point the grain boundaries and 
grain interior can account for the strength of polycrystalline materials, on development of cell structure at $\varepsilon=0.34$, the cell wall and cell interior will contribute further strengthening. If it is assumed that the strength of the cell interior at a large strain is comparable to that of the grain interior at yield point, then $\Delta \sigma_{\mathrm{o}}$ in eq. (6) can be expressed as follows:

$\Delta \sigma_{o}=2 f_{w} \sigma_{o y}+\left(1-f_{w}\right) \sigma_{o y}$

or

$\Delta \sigma_{o}=\left(1+f_{w}\right) \sigma_{o y}$

Here, $f_{w}$ is the volume fraction of the cell wall. However, the difference in dislocation densities in the cell wall and cell interior introduces some internal stress, which in turn can influence $f_{w}$. Now, eq. (5) can be rewritten as

$\Delta \sigma=\left(1+f_{w}\right) \sigma_{o y}+\Delta k d^{-0.5}$

This equation suggests that strengthening due to substructural evolution, viz., comprising of cell interior and cell wall $\left(\mathrm{f}_{\mathrm{w}}=\left(\mathrm{d}_{\mathrm{w}}\right) /\left(\mathrm{d}_{\mathrm{w}}+\mathrm{d}_{\mathrm{ci}}\right)\right)$, and grain interior resistance $\left(\sigma_{\text {oy }}\right)$ mutually balance so as to result in a constant value of $\Delta \sigma_{\mathrm{o}}$ that is independent of grain size. In fact, for the strain increment of $0.34-0.002, \mathrm{f}_{\mathrm{w}}$ obtained at different temperatures were jointly determined to be independent of grain size. Equation (5a) can be used to estimate the value of $f_{w}$ from the Hall-Petch data, but it was found to be unrealistically larger than the one experimentally obtained. For example, at the test temperature of $297 \mathrm{~K}, \mathrm{f}_{\mathrm{w}}=1.65$ was estimated from eq. (5a) against the experimental value of 0.61 . Such a deviation might result from the following sources:

1. the ratio of the strengths of the cell wall to the cell interior assumed here $\left(\sigma_{\mathrm{w}}=2 \sigma_{\mathrm{c}}\right)$,

2. the strengths of the cell interior taken to be comparable with the strength of the grain interior at yield point,

3. histograms of cell parameters not considered for their distributed effects on strengthening. The smaller cell sizes and larger cell wall thickness rather than the average sizes may be more effective resistance to dislocation motion. This is because the cell walls are much weaker barriers than the grain boundaries, and only when the cell size is very small can large proportion of cell walls surpass the grain boundary strengthening contribution.

\section{Conclusions}

The flow stress follows the Hall-Petch type relationship in type $316 \mathrm{~L}$ stainless steel. However, the stress increment between yield point and $34 \%$ strain increases with grain size at 673 and $973 \mathrm{~K}$ but decreases at $297 \mathrm{~K}$, due to the difference in the nature of dislocation and cell structure in the vicinity of grain boundaries and in the grain interior. Due to the cell formation at large strains, the grain interior contributes to strengthening of polycrystalline materials more than the contribution from grain boundaries. The cell wall thickness is found to be larger than the cell interior size; and the two together affect the nature of relative contributions of grain interior and grain boundaries to polycrystalline strengthening. The maximum grain interior strengthening occurs at $673 \mathrm{~K}$ because dynamic strain aging at this temperature results in higher dislocation density to create finer cell sizes and thicker cell walls.

\section{References}

[1] Hall EO. Proc Phys Soc London 1951;B64:747.

[2] Petch NJ. J Steel Inst 1953;174:25.

[3] Courtney TH. Mechanical behavior of materials. Singapore: McGraw-Hill Publishing Co., 1990.

[4] Young CM, Sherby OD. J Iron Steel Inst 1973;211:640.

[5] Kashyap BP, McTaggart K, Tangri K. Phil Mag A 1988;57:97.

[6] Kashyap BP, Tangri K. Acta Metall Mater 1995;43:3971.

[7] Nix WD, Gibeling JC, Hughes DA. Metall Trans A 1985;6A:2215.

[8] Mughrabi H, Ungar T, Kienle W, Wilkens M. Phil Mag A 1986;53:793.

[9] Neuhaus R, Schwink C. Phil Mag A 1992;65:1463.

[10] Meyers MA, Chawla KK. Mechanical metallurgy: principles and applications. Englewood Cliffs, New Jersey: Prentice-Hall Inc., 1984.

[11] Ashby MF. Phil Mag 1970;21:399.

[12] McTaggart, K., MSc Thesis, University of Manitoba, Winnipeg, 1987.

[13] Baker I, Liu L, Mandal D. Scr Metall Mater 1995;32:167. 
[14] Mandal D, Baker I. Scr Metall Mater 1995;33:831.

[15] GilSevillano J, Aernoudt E. Mater Sci Eng 1987;86:35.

[16] Estrin Y, Toth LS, Molinari A, Brechet Y. Acta Metall Mater 1998;46:5509.

[17] Kuhlmann-Wilsdorf D. Phil Mag A 1999;79:955.

[18] Kuhlmann-Wilsdorf D. Trans Metall Soc AIME 1966;79:1047.

[19] Kuhlmann-Wilsdorf D. Mater Res Innov 1998;1:265.

[20] Polukhin P, Gorelik S, Vorontsov V. Physical principles of plastic deformation. Moscow: Mir Publishers, 1983.
[21] Mecking H. In: Thompson AW, editor. Work hardening in tension and fatigue. New York: Am Inst Min Metall Petro Engrs Inc.; 1975. p. 6-7.

[22] Jackson PJ. Progr Mater Sci 1985;29:139.

[23] Zaiser M, Bay K, Hahner P. Acta Mater 1999;47:2463.

[24] Stanley HE. In: Bunde A, Havlin S, editors. Fractals and disordered systems. Berlin: Springer; 1991. p. 3-9.

[25] Hansen N, Kuhlmann-Wilsdorf D. Mater Sci Eng 1986;81:141

[26] Sikka VK, Nahm H, Moteff J. Mater Sci Eng 1975;20:55. 